\title{
Ethnic Differences in Children's Entry into Public Mental Health Care via Emergency Mental Health Services
}

\author{
Lonnie R. Snowden · Mary C. Masland • \\ Kya Fawley $\cdot$ Neal Wallace
}

Published online: 5 February 2009

(C) The Author(s) 2009. This article is published with open access at Springerlink.com

\begin{abstract}
For children and youth making a mental health crisis visit, we investigated ethnic disparities in whether the children and youth were currently in treatment or whether this crisis visit was an entry or reentry point into mental health treatment. We gathered Medicaid claims for mental health services provided to 20,110 public-sector clients ages 17 and younger and divided them into foster care and non-foster care subsamples. We then employed logistic regression to analyze our data with sociodemographic and clinical controls. Among children and youth who were not placed in foster care, African Americans, Latinos, and Asian Americans were significantly less likely than Caucasians to have received mental health care during the three months preceding a crisis visit. Disparities among children and youth in foster care were not statistically significant. Ethnic minority children and youth were more likely than Caucasians to use emergency care as an entry or reentry point into the mental health treatment, thereby exhibiting a crisis-oriented pattern of care.
\end{abstract}

L. R. Snowden $(\bowtie) \cdot$ K. Fawley

School of Social Welfare, University of California Berkeley,

120 Haviland Hall, Berkeley, CA 94720, USA

e-mail: snowden@berkeley.edu

K. Fawley

e-mail: kfawley@berkeley.edu

\section{C. Masland}

Center for Mental Health Services Research,

University of California Berkeley, Berkeley, CA, USA

N. Wallace

Mark O. Hatfield School of Government, Portland State

University, Portland, OR, USA
Keywords Children - Race - Emergency · Crisis · Mental health

\section{Introduction}

For too many children and youth in crisis, hospital-based and other crisis service programs are an initial point of contact with the mental health system (Kalogerakis 1992). These children may be making physical threats or committing other acts of aggression, exhibiting oppositional conduct and defiance reaching unmanageable proportions, having suicidal thoughts or making suicidal gestures. Suicide attempts, which are the most common reasons youth visit the psychiatric emergency room (Halamandaris and Anderson 1999), are now the third leading cause of death among adolescents (U.S. Public Health Service 2001).

Unmanaged mental health crises can have far-reaching consequences. They sometimes result in injury to the child or youth in psychiatric distress or to others, and can otherwise bother families, schools, and communities. Ultimately, the young person in crisis may require psychiatric hospitalization or another form of confinement. Along with their adverse human consequences, unmanaged crises impose a financial burden on communities, treatment systems, and society at large (Hargreaves et al. 1998).

Ethnic minority persons are especially likely to exhibit crisis-oriented patterns of mental health care, contributing to the lower quality of mental health care provided to members of ethnic minority groups. Speaking of African Americans, the Surgeon General asserted that: "Mental health care occurs relatively frequently in emergency rooms and psychiatric hospitals. These settings and patterns of treatment undermine delivery of high-quality mental health care" (U.S. Public Health Service 2001, 
p. 68). The Surgeon General was concerned that, by shifting the occasion and loci of care to crisis services, mental health systems deny ethnic minority persons access to treatments that are not available on an urgent care basis, as well as denying them opportunities for problem monitoring and reinforcement of therapeutic gains.

Because they have been abused and neglected, children and youth supervised by the child welfare system often are at psychiatric risk. This high risk promotes child welfare personnel's greater awareness of mental health problems and more screening, resulting in higher rates of mental health treatment for children and youth involved in the child welfare system (Garland et al. 2001; Leslie et al. 2004; Rubin et al. 2004). This vigilance might reduce ethnic disparities in crisis-oriented patterns of care by helping to overcome both cultural and systemic barriers that prevent some minorities from seeking and/or accessing mental health care.

Most studies reported to date overlook possible ethnic disparities in the role of crisis services as an initial point of contact with the mental health system. They focus instead on disparities in levels of crisis services use, asking whether members of ethnic minority populations are at greater risk of receiving crisis treatment than Caucasians. Findings from a large California sample indicated that African American and Native American children and youth were indeed more likely to use mental health crisis care than Caucasians, and that Latino and Asian children and youth used intensive crisis services targeting the most serious kinds of crises (Snowden et al. 2008).

Minority children and youth's access to non-crisis services is less then that of Caucasian children and youth (Snowden and Yamada 2005). One review of 11 studies on mental health care for African American adolescents found that in the majority of studies, African American adolescents received less mental health treatment, including outpatient care, than Caucasian adolescents (Elster et al. 2003). Elsewhere, investigators reported that Latino children received fewer counseling sessions and specialty mental health services than Caucasian children (Pumariega and Rothe 2003). Without directly addressing pre-crisis care, these findings imply that ethnic minority crisis services users have less mental health treatment than Caucasian users before making a crisis care visit.

The present study investigated ethnic disparities in utilization of mental health crisis services as a point of entry or reentry into the mental health services system. Our focus was on child and adolescent users of crisis services receiving Medicaid-financed public-sector mental health treatment. We asked whether African Americans, Latinos Asian Americans, and Native Americans were less likely than Caucasians to have received treatment prior to a crisis visit, or whether they previously were out of treatment for at least 90 days.
We asked these questions for a sub-sample of children and youth placed in foster care and a sub-sample of children and youth who were not in foster care. We separated foster care and non-foster children and youth into two subsamples, because child welfare authorities recognize that foster care-placed children and youth are likely to have significant mental health-related needs and refer them for treatment accordingly. Because foster care acts as a gatekeeper for Caucasian and minority children and youth alike, we expected that disparities in treatment received prior to crisis care would be less for foster care-placed children and youth than for children and youth who were not in foster care.

\section{Method}

\section{Data Sources}

The California Department of Mental Health provided Medi-Cal (California's Medicaid program) paid claims for mental health services delivered to children and youth under age 18, between July 1, 1998 and June 30, 2001. The claims records included the child's age, gender, ethnicity, whether the child had a disability that made him/her eligible for Supplementary Social Security Income (SSI), and primary diagnosis, as well as the date, cost and type of the service. We obtained foster care placement records for all Californian children and youth under 18 for fiscal years 1999, 2000, and 2001 from the California Department of Social Services. Approval to use these data for research purposes was obtained from the University of California Berkeley's Institutional Review Board and the California Health and Human Services Agency's Committee for the Protection of Human Subjects.

The Medi-Cal claims data and child welfare records were then merged using probabilistic matching techniques. Our procedure was as follows. We identified each child or youth for whom a mental health claim had been submitted listing a foster care billing code, and we matched his or her mental health record with his or her child welfare records for the years of our study. Files were matched using Medicaid-ID number, social security number, name, address, gender, date of birth and ethnicity. We were successful in finding a matching child welfare record for more than $95 \%$ of children and youth where the mental health billing code indicated foster care placement (Libby 2004). The result was a data set with foster care and mental health service use listed for each child. Unique encrypted identifiers were used to track the children's foster care status and mental health service use for all three years.

This data set was originally created for a study of the mental health service utilization of foster care-placed 
children (Libby 2004) and it has also been used for a multiyear study of ethnic disparities in children's use of crisis services supported by the National Institute of Mental Health. A previous paper reports on ethnic differences in probability and intensity in use of crisis stabilization and crisis intervention services (Snowden et al. 2008).

\section{Sample}

From this data set we selected children and youth who had received two kinds of crisis services recognized and recorded under California's Medicaid program, "MediCal": crisis stabilization and crisis intervention. Crisis stabilization services, accounting for about $1.6 \%$ of visits (Snowden et al. 2008), are designed for the most serious crises. They are provided in hospitals, including general emergency rooms and psychiatric emergency rooms, or in other 24-hour health care facilities. Crisis intervention services, accounting for about $10.7 \%$ of visits (Snowden et al. 2008), are designed for less urgent crises. They are provided in the community, and generally include assessment, evaluation, collateral care, and therapy. Crisis intervention services are for clients needing urgent assistance, but where the crisis is not serious enough to warrant confinement or removal from the community.

We observed whether any treatment was recorded during the 90 days before a crisis visit. We chose a 90-day pre-crisis interval because, whether or not the client was new, the crisis visit in question was beyond the boundary of a treatment episode.

Our approach to defining treatment episodes was drawn from previous mental health services research. In this tradition, a sequence of treatment becomes an episode when care is provided without lengthy intersession gaps (Foster 2000; Goldman et al. 1987). For children and youth, intersession gaps of 30 and 90 days have been used to define the end of one episode and the beginning of another (Cohen et al. 2006). We chose 90 days rather than 30 days without treatment as our standard, because 90 days gives wider scope for pre-crisis treatment to occur. We can be more confident with 90 day treatment gaps than with 30 day gaps that clients without pre-crisis services were entering the mental health system for the first time or were reentering the system after effectively being out of treatment.

In order to identify a pre-crisis observation period lasting 90 days, we focused on the first crisis visit of the year and we ignored subsequent crisis visits, if any. We then counted 90 days before the first visit and examined the client's use of non-crisis mental health services. To avoid censoring (less than 90 days elapsed time between the beginning of the fiscal year and the first visit), we selected clients who experienced their first crisis visit at least three months after the beginning of the fiscal year. Each client could appear only once during each fiscal year, representing the first crisis visit, but he or she might appear more than once in our data by making crisis visits in multiple years. Our statistical procedures adjusted for the impact of observing the same client more than once.

Our final sample consisted of 16,843 children and youth who were not in foster care and 3,267 youth who were in foster care and who had a first crisis intervention or crisis stabilization service during the study period. Most children and youth in foster care lived with foster families but, during the study years, about $7 \%$ of California's foster care-placed children resided in group homes or residential treatment centers (Center for Social Services Research 2007). We do not know how many members of our sample lived in these facilities during the 90 days before their first crisis visit.

Descriptive information on our sample is shown in Tables 1 and 2. We tested non-foster care/foster care differences using chi-square. Slightly more than half of the non-foster care (52\%) and foster care-placed subsamples (54\%) were minorities. Most children and youth in both groups were between the ages of 12-17, however, the foster care group had more 6-11 year-olds (43\%), than the non-foster care sub-sample (29\%). The most common diagnosis was a mood disorder. Forty percent of the

Table 1 Demographic characteristics of sample by foster care status

\begin{tabular}{|c|c|c|c|}
\hline Demographics & $\begin{array}{l}\text { Non-foster } \\
(n=16,843) \\
N(\%)\end{array}$ & $\begin{array}{l}\text { Foster } \\
(n=3267) \\
N(\%)\end{array}$ & $X^{2}$ \\
\hline Ethnicity & & & $23.71 * *$ \\
\hline Caucasian & $8,061(48)$ & $1,521(46)$ & \\
\hline African American & $3,522(21)$ & 712 (22) & \\
\hline Hispanic & $3,885(23)$ & $771(24)$ & \\
\hline Asian & $821(5)$ & $163(5)$ & \\
\hline Native American & $190(1)$ & $59(2)$ & \\
\hline Other ethnicity & $364(2)$ & $41(1)$ & \\
\hline Ages & & & $298.70 * *$ \\
\hline $0-3$ & $113(1)$ & $27(1)$ & \\
\hline $4-5$ & $408(2)$ & $146(4)$ & \\
\hline $6-11$ & $4,959(29)$ & $1,398(43)$ & \\
\hline $12-17$ & $11,363(67)$ & $1,696(52)$ & \\
\hline Fiscal year & & & $18.02 * *$ \\
\hline 1999 & 4,995 (29) & $1,036(32)$ & \\
\hline 2000 & $5,693(34)$ & $1,164(35)$ & \\
\hline 2001 & $6,155(37)$ & $1,067(33)$ & \\
\hline Gender & & & $55.08 * *$ \\
\hline Male & $9,331(55)$ & $1,579(48)$ & \\
\hline SSI eligibility for disability & & & $106.21 * *$ \\
\hline Eligible & $2,942(17)$ & $333(10)$ & \\
\hline
\end{tabular}

$* p<.05, * * p<.01, * * * p<.001$ 
Table 2 Diagnostic characteristics of sample by foster care status

\begin{tabular}{lcc}
\hline Diagnosis & $\begin{array}{l}\text { Non-foster care } \\
(n=16,843)\end{array}$ & $\begin{array}{l}\text { Foster care } \\
(n=3267) \\
\mathrm{N}(\%)\end{array}$ \\
\hline Developmentally disabled & $195(1)$ & $25(1)$ \\
ADHD & $1,377(8)$ & $136(4)$ \\
Disruptive behavior & $1,551(9)$ & $189(6)$ \\
Adjustment disorder & $1,937(12)$ & $469(14)$ \\
Anxiety disorder & $1,170(7)$ & $207(6)$ \\
Psychotic & $787(5)$ & $81(2)$ \\
Mood disorder & $6,791(40)$ & $889(27)$ \\
Personality disorder & $8(0)$ & $0(0)$ \\
Eating disorder & $25(0)$ & $3(0)$ \\
Substance abuse & $249(1)$ & $31(1)$ \\
Somatization & $17(0)$ & $1(0)$ \\
Other diagnosis & $2,190(13)$ & $327(10)$ \\
\hline
\end{tabular}

Note: Non-foster care vs. foster care difference statistically significant: $\left.\mathrm{X}^{2}=260.30, p<.01\right)$

children and youth who were not placed in foster care and $27 \%$ of the youth in foster care were given this diagnosis.

\section{Study Variables}

The dependent variable in our analysis was a comprehensive indicator of specialty mental health pre-emergency treatment in the 90 days prior to the crisis visit. The variable was coded as a "yes" or "no." "Yes" indicated that the client had had any previous mental health treatmentas few as one contact with any service- provided by the mental health treatment system, including inpatient, outpatient, case management, and day treatment care.

Our independent variables were characteristics that are potentially correlated with receiving mental health care as well as potentially correlated with race and ethnicity. Independent variables entered as covariates were: age, gender, diagnosis, if the child qualified for Supplemental Social Security (SSI) due to a physical or mental disability, if the child was placed in foster care with a relative (kinship care), county of residence, and year of observation. SSI eligibility due to a disability was included as a covariate because children and youth with disabilities are more likely to receive mental health treatment (DosReis et al. 2001; Harman et al. 2000; Witt et al. 2003). Similarly, in our foster care subsample, kinship care was included as a covariate because children in kinship care are less likely than other foster care-placed children and youth to receive mental health services (Leslie et al. 2000).

Additionally, we included cross-sectional fixed effects to control for each person's county of residence. This control was introduced because, in keeping with California's geographic and sociopolitical diversity, California's public mental health services are decentralized to the county level. County environments vary, and county mental health treatment systems vary in how they provide for and organize crisis services and other mental health care, and these differences might bias our empirical estimates.

Our county fixed effects eliminated artifacts attributable to overrepresentation of minority children and youth in certain counties perhaps having higher rates of crisis services use. Finally, we included longitudinal fixed effects indicating in which of the three fiscal years mental health care was observed. These fixed-effects controlled for observed and unobserved differences between fiscal years, including effects due to observing some clients in multiple fiscal years.

Analysis

We estimated the odds of receiving mental health treatment in the 90 days preceding a crisis visit with logistic regression. We estimated separate models for children and youth in foster care and who were not in foster care. In both models, independent variables of primary concern described ethnic group membership. Dummy variables separately compared African Americans, Latinos, Asian Americans, Native Americans.

Persons who were not assigned to one of these ethnic categories were assigned to another category, "other ethnicities". "Other ethnicities" is too disparate a category to permit meaningful interpretation, and we included it only to maintain the integrity of our sample. We controlled for the impact of "other ethnicities" by creating a dummy variable, comparing "other ethnicities" with Caucasians.

Additional independent variables controlled for age, gender, diagnosis, disability (whether the child or youth qualified for Supplemental Social Security (SSI) due to a physical or mental disability), county of residence, and fiscal year. If the child or youth was in foster care, we entered a variable indicating whether or not the placement was in kinship foster care.

\section{Results}

Our sample included 16, 843 first crisis service events provided to 15,896 children and adolescents who were not in foster care, and 3,267 first crisis service events provided to 3222 foster care-placed children and adolescents. The percentages of children and youth in each ethnic group who received specialty mental health care prior to their crisis visit are shown in Table 3. Chi-square tests were used to test differences between the foster care sample and the nonfoster care sample. Slightly higher percentages of children 
Table 3 Percentage of youth who received mental health services in the 90 days prior to their crisis visit by foster care status and ethnicity

\begin{tabular}{|c|c|c|c|c|}
\hline Ethnicity & Outpatient $N(\%)$ & Case management $N(\%)$ & Inpatient $N(\%)$ & Day treatment $N(\%)$ \\
\hline \multicolumn{5}{|l|}{ Not in foster care $(n=16,843)$} \\
\hline Caucasian $(n=8061)$ & $4756(59)$ & $2176(27)$ & $403(5)$ & $645(8)$ \\
\hline African American $(n=3522)$ & $1761(50)$ & $740(21)$ & $141(4)$ & $247(7)$ \\
\hline Latino $(n=3885)$ & $1748(45)$ & $816(21)$ & $155(4)$ & $194(5)$ \\
\hline Asian $(n=821)$ & $386(47)$ & $197(24)$ & $25(3)$ & $33(4)$ \\
\hline Native American $(n=190)$ & $87(46)$ & $44(23)$ & $4(2)$ & $8(4)$ \\
\hline Other ethnicity $(n=364)$ & $200(55)$ & $113(31)$ & $36(10)$ & $18(5)$ \\
\hline \multicolumn{5}{|l|}{ In foster care $(n=3267)$} \\
\hline Caucasian $(n=1521)$ & $684(45)$ & $335(22)$ & $61(4)$ & $106(7)$ \\
\hline African American $(n=712)$ & $249(35)$ & $107(15)$ & $28(4)$ & $64(9)$ \\
\hline Latino $(n=771)$ & $247(32)$ & $123(16)$ & $23(3)$ & $54(7)$ \\
\hline Asian $(n=163)$ & $59(36)$ & $34(21)$ & $2(1)$ & $11(7)$ \\
\hline Native American $(n=59)$ & $16(27)$ & $9(15)$ & $2(3)$ & $3(5)$ \\
\hline Other ethnicity $(n=41)$ & $18(44)$ & $8(20)$ & $5(12)$ & $4(10)$ \\
\hline
\end{tabular}

Note: Non-foster care vs. foster care differences statistically significant for: Outpatient $\left(\mathrm{X}^{2}=45.36, p<.01\right)$, Case management $\left(\mathrm{X}^{2}=210.63\right.$, $p<.01)$

and youth who were not in foster care received outpatient treatment $\left[\mathrm{X}^{2}(1)=45.36, p<.01\right]$, and case management services $\left[\mathrm{X}^{2}(1)=210.63, p<.01\right]$ than children and youth in foster care.

Table 4 presents results from the multivariate analysis for children and youth who were not in foster care. African American $(\mathrm{OR}=.579,95 \% \mathrm{CI}=.526-.637)$ and Latino $(\mathrm{OR}=.575,95 \% \mathrm{CI}=.527-.628)$ crisis service recipients had lower odds of prior mental health treatment than the Caucasian crisis service recipients, as did Asian American children and youth $(\mathrm{OR}=.499,95 \% \mathrm{CI}=.425-.586)$.

Table 4 Adjusted odds of receipt of any mental health services 90 days prior to crisis visit by ethnicity

\begin{tabular}{ll}
\hline Variable & OR $(95 \% \mathrm{CI})$ \\
\hline Not in foster care & \\
African American & $.579(.526, .637)$ \\
Latino & $.575(.527, .628)$ \\
Asian & $.499(.425, .586)$ \\
Native American & $.794(.569,1.11)$ \\
In foster care & \\
African American & $.813(.6441 .02)$ \\
Latino & $.873(.703,1.08)$ \\
Asian & $.840(.566,1.25)$ \\
Native American & $.577(.295,1.13)$ \\
\hline
\end{tabular}

Note: Caucasian is the reference group. Models control for age, gender, diagnosis, SSI disability, county of residence, and year of observation. In the foster care sample, another control variable was kinship foster care (34\%) versus other foster care $(66 \%)$. Kinship care was significant: $(\mathrm{OR}=.760, \mathrm{CI}=.609, .946)$
Native American children and youth also had a lower probability of prior mental health treatment than Caucasian children and youth, but this difference was not statistically significant $(\mathrm{OR}=.794,95 \% \mathrm{CI}=.569-1.11)$.

Table 4 also presents results from the multivariate analysis for children and youth in the foster care sample. While African American, Latino, Asian, and Native American children and youth had lower odds than Caucasians of receiving pre-crisis public mental health treatment 90 days before a crisis visit, the results were not statistically significant.

The minority-Caucasian odds ratios observed in the foster care sample were not statistically significant from zero, but this does not insure that they were significantly different from corresponding odds ratios in the non-foster care sample. To directly compare foster care and nonfoster care samples, we combined the samples and created a dummy variable indicating to which sample participants belonged. We again estimated the odds of receiving mental health treatment in the 90 days preceding a crisis visit with logistic regression from covariates described above, as well as from the dummy variable indicating membership in foster care versus non-foster care sample and terms indicating interaction between foster care versus non-foster care status and ethnicity. We found that differences for Latinos $(\mathrm{OR}=1.400,95 \% \mathrm{CI}=1.135$ 1.726) and Asian Americans $(\mathrm{OR}=1.534 \quad 95 \%$ $\mathrm{CI}=1.050-2.238$ ) were greater in the non-foster care than in the foster care sample. Differences for African Americans $\quad(\mathrm{OR}=1.233,95 \% \quad \mathrm{CI}=.896-1.41) \quad$ and Native Americans $(\mathrm{OR}=.704 \quad 95 \% \quad \mathrm{CI}=.361-1.370)$ were not significantly different. 


\section{Discussion}

Among non-foster care children and youth using Medicalfunded public mental health services in California, African American, Latino, and Asian American children and youth crisis care recipients were less likely to have had previous contact with the mental health treatment system than their Caucasian counterparts. These results were observed after controlling for several key, potentially confounding variables, including gender, age, diagnosis, disability status, county of residence, and year of visit. Thus, minority children and youth crisis services users were more likely than Caucasians to be entering mental health treatment anew or reentering treatment after a 90-day delay.

We did not find greater crisis care entry or reentry for Native American children and youth. Native Americans' probability of pre-crisis services use was lower than that of Caucasian children and youth, but the difference did not reach statistical significance. Our Native American sample was smaller than our other ethnic group samples, and the failure to detect significant findings for Native Americans may be due to a lack of power.

For children and adolescents placed in foster care, ethnic minority children and adolescents had lower odds of precrisis treatment, but these differences were not statistically significant. Further analysis revealed that for Latino and Asian American children and adolescents, the odds of precrisis treatment in the foster care sample were lower than odds in the non-foster care sample. Thus, for Latinos and Asian Americans, there was clear-cut evidence that foster care placement was not associated with crisis treatment disparities. This difference may be due to a higher level of mental health screening for children and youth placed in foster care. Indeed, during the years of our study, California's mental health policy came to require that the most seriously disturbed children and youth placed in foster care be screened for mental illness and provided with necessary outpatient care (California Department of Mental Health 2001). In the foster care system, ethnic disparities remain in providing access to mental health treatment (Garland et al. 2005). However, the greater attention paid to mental health problems in foster care may reduce disengagement from the mental health treatment system for Latino and Asian American children and adolescents and may shrink minority-white disparities. Entering the child welfare system gives workers the authority to screen for mental health problems and to make and monitor referrals. However undesirable it may otherwise be, this vesting of authority in child welfare personnel might dissolve some of the barriers that bar Latino and Asian American children and adolescents from mental health treatment. More research is needed on mental health screening and monitoring in foster care, and its impact on ethnic disparities.
Reports in the literature identify several obstacles that prevent minorities from using routine outpatient treatment. These obstacles include avoidance of defining personal distress as mental illness due to stigma and a preference for culturally sanctioned alternatives (Pumariega et al. 2005; Roberts et al. 2005), mistrust of providers and of the mental health treatment system (Thompson et al. 2004), and limited proficiency in English (Fiscella et al. 2002). By preventing them from seeking other forms of mental health treatment, and in so doing, by entering the mental health treatment system via non-emergency care routes, these obstacles appear to channel minorities into crisis care.

Although less often considered than individual and family characteristics, characteristics of local environments and mental health treatment systems may channel ethnic minority children and youth away from non-crisis care and toward crisis care. Treatment systems and their sociopolitical environments vary greatly state-to-state, and these differences can affect treatment opportunities (Sturm et al. 2003). For example, Sturm and colleagues (2003) found that, in Alabama, children from poor families are more likely to get mental health treatment than children in wealthy families, but, in California, children from wealthy families are more likely to receive certain mental health services than children in poor families. Furthermore, in states where mental health care is decentralized to the county level, treatment systems can vary between counties. In California, some counties are faster at authorizing mental health services than others, and this difference affects treatment access (Masland et al. 2007).

An investigation of the impact of county characteristics on ethnic disparities in treatment entry or reentry through crisis care- the present focus of concern-requires its own theoretical and methodological approach, and, therefore, was beyond the scope of the present study. However, more research is needed to evaluate which system-level differences affect disparities in pre-crisis treatment disengagement. Researchers should pay particular attention to characteristics that affect local community conditions and the mental health system's capacity to treat ethnic minority children and youth.

Although our finding that children who are in foster care were less likely to receive case management and outpatient care contrasts with the results of other studies in which foster care-placed children are more likely than children outside the child welfare system to use mental health treatment (Halfon et al. 1992), our sample may be unique because it consisted entirely of children and youth who used crisis services. It is possible that among children in foster care, crisis service users are less likely to be in outpatient treatment.

Several limitations must be borne in mind when considering our findings. One is that we could not directly observe how children and youth enter crisis services- 
who brings them in, with what presenting complaint, how emergency clinicians respond-nor could we directly observe attitudes and cultural beliefs about treatment or observe past mental health treatment experiences. Conceivably, caretakers in some ethnic minority communities mistrust treatment programs and personnel (Thompson et al. 2004), and avoid seeking care until troubling behavior has reached crisis proportions. These and other attitudes and practices may explain why ethnic minority children and adolescent do not participate in treatment until forced to do so by conditions of crisis. Measuring these variables and including them in explanatory models will lead to a more comprehensive understanding of ethnic disparities in patterns of mental health service utilization.

Another limitation is that we could not observe visits to providers outside of the public mental health treatment system or to non-mental health specialists. Thus, while our data record all Medi-Cal funded specialty services, they do not record any visits that were paid for by non-Medi-Cal public or private sources. Nor did they record visits to primary care physicians or to healthcare providers not covered by Medicaid, or to school-based services.

On the other hand, minority children and youth's lack of access to mental health care is pervasive (Elster et al. 2003; Pumariega and Rothe 2003; Snowden and Yamada 2005). In view of widespread minority under-representation in care, it seems unlikely that visits to primary care physicians or school-based clinics would offset specialty mental health care visits for minority children and youth especially.

This study is also limited by the definition of prior mental health treatment, which included contact with several different types of services, and did not distinguish between them. Furthermore, we required that crisis services users have only one previous contact with the mental health treatment system to consider their crisis visit to have occurred in the context of a treatment episode. One contact includes screening appointments, single outpatient sessions, and other services considered of little value when provided on their own. If this study had examined the quality of mental health services provided to minority children and youth, it might have uncovered even greater disparities.

Despite this limitation, results from the study strongly indicate that whether entering or reentering the mental health treatment system, ethnic minority children and youths' initial point of contact with mental health treatment tends to occur via crisis services. By being isolated from the mental health treatment system until they are in crisis, minority children and youth do not obtain the monitoring and management and the chance to make therapeutic gains, which might prevent the need for crisis care.
Acknowledgments This research is supported by National Institute of Mental Health award R01 MH067871. The results from this paper were displayed as a poster presentation entitled: "Psychiatric crisis services as entry point into public mental health care for ethnic minority children and youth." The poster was presented at the AcademyHealth annual research meeting in Orlando, Florida on June 3-5 2007. Additionally, the results for African American children and youth presented in the paper were part of a poster entitled: "Disparities in utilization of crisis services among African American and Caucasian children in California's public mental health system." This poster was presented at the Society for Social Work Research's annual conference in San Francisco, CA on January 11-14 2007.

Open Access This article is distributed under the terms of the Creative Commons Attribution Noncommercial License which permits any noncommercial use, distribution, and reproduction in any medium, provided the original author(s) and source are credited.

\section{References}

California Department of Mental Health. (2001). DMH letter 01-03. CA: Sacramento. August 8th, 2001.

Center for Social Services Research. (2007). In and out of county placement grids. http://cssr.berkeley.edu/ucb_childwelfare/place mentgrids.aspx.

Cohen, E., Snowden, L. R., Libby, A., \& Ma, Y. (2006). The effects of capitation on outpatient mental health episodes of young children. Journal of Child and Family Studies, 15, 13-26.

DosReis, S., Zito, J. M., Safer, D. J., \& Soeken, K. L. (2001). Mental health services for youths in foster care and disabled youths. American Journal of Public Health, 91, 1094-1099.

Elster, A., Jarosik, J., Van Geest, J., \& Fleming, M. (2003). Racial and ethnic disparities in health care for adolescents: A systematic review of the literature. Archives of Pediatric and Adolescent Medicine, 157, 867-874.

Fiscella, K., Franks, P., Doescher, M. P., \& Saver, B. G. (2002). Disparities in health care by race, ethnicity and language among the insured: Findings from a national sample. Medical Care, 40, $52-59$.

Foster, E. M. (2000). Does the continuum of care reduce inpatient length of stay? Evaluation and Program Planning, 23, 53-65.

Garland, A. F., Hough, R., McCabe, K., Yeh, M., Wood, P., \& Aarons, G. (2001). Prevalence of psychiatric disorders in youths across five sectors of care. Journal of the American Academy of Child and Adolescent Psychiatry, 40, 409-418.

Garland, A. F., Lau, A. S., Yeh, M., McCabe, K., Hough, R., \& Landsverk, J. (2005). Racial and ethnic differences in utilization of mental health services among high-risk youths. American Journal of Psychiatry, 162, 1336-1343.

Goldman, H. H., Scheffler, R. M., \& Cheadle, A. (1987). Demand for psychiatric services: A clinical model for specifying "the product". Advances in Health Economics and Health Services Research, 8, 255-273.

Halamandaris, P. V., \& Anderson, T. R. (1999). Child and adolescents in the psychiatric emergency setting. The Psychiatric Clinics of North America, 22, 865-876.

Halfon, N., Berkowitz, G., \& Klee, L. (1992). Mental health service utilization by children in foster care in California. Pediatrics, 89 , $1238-1244$.

Hargreaves, W. A., Shumway, M., Hu, T., \& Cuffel, B. (1998). Costoutcome methods for mental health. New York: Academic Press.

Harman, J. S., Childs, G. E., \& Kellcher, K. J. (2000). Mental health care utilization and expenditures among children in foster care. 
Archives of Pediatrics and Adolescent Medicine, 154, 11141117.

Kalogerakis, M. G. (1992). Emergency evaluation of adolescents. Hospital and Community Psychiatry, 43, 617-621.

Leslie, L. K., Hurlburt, M., Landsverk, J., Barth, R., \& Sylmen, D. (2004). Outpatient mental health services for children in foster care: A national perspective. Child Abuse and Neglect, 28, 699714.

Leslie, L. K., Landsverk, J., Ezzet-Lofstrom, R., Tschann, J. M., Slyman, D. J., \& Garland, A. F. (2000). Children in foster care: Factors influencing outpatient mental health service use. Child Abuse and Neglect, 24, 465-476.

Libby, A. M. (2004). Mental health care and foster care interaction. CA: California HealthCare Foundation.

Masland, M., Snowden, L. R., \& Wallace, N. (2007). Assessment, authorization and access to Medicaid managed mental health care. Administration and Policy in Mental Health and Mental Health Services Research, 34, 548-562.

Pumariega, A. J., Rogers, K., \& Rothe, E. (2005). Culturally competent systems of care for children's mental health: Advances and challenges. Community Mental Health Journal, $41,539-555$.

Pumariega, A. J., \& Rothe, E. (2003). Cultural considerations in child and adolescent psychiatric emergencies and crises. Child and Adolescent Psychiatric Clinics of North America, 12, 723-744.

Roberts, R. E., Alegria, M., Roberts, C. R., \& Chen, I. G. (2005). Mental health problems of adolescents as reported by their caregivers: A comparison of European, African, and Latino Americans. Journal of Behavioral Health Services \& Research, $32,1-13$.

Rubin, D. M., Alessandrini, E. A., Feudtner, C., Mandel, D., Localio, A., \& Hadley, T. (2004). Placement stability and mental health costs for children in foster care. Pediatrics, 113, 1336-1341.

Snowden, L. R., Masland, M. C., Libby, A. M., Wallace, N., \& Fawley, K. (2008). Ethnic minority children's use of psychiatric emergency care in California's public mental health system. American Journal of Public Health, 98, 118-124.

Snowden, L. R., \& Yamada, A. (2005). Cultural differences in access to care. Annual Review of Clinical Psychology, 1, 143-166.

Sturm, R., Ringel, J. S., \& Andreyeva, T. (2003). Geographic disparities in children's mental health care. Pediatrics, 112(4), e308.

Thompson, V. L., Bazile, A., \& Akbar, M. (2004). African Americans' perceptions of psychotherapy and psychotherapists. Professional Psychology-Research and Practice, 35, 19-26.

U.S. Public Health Service, Department of Health and Human Services. (2001). Mental health: Culture, race, and ethnicity- a supplement to mental health: A report of the surgeon general. Md: Rockville.

Witt, W. P., Kasper, J. D., \& Riley, A. W. (2003). Mental health services use among school-aged children with disabilities: The role of sociodemopgraphics, functional limitations, family burdens, and care coordination. Health Services Research, 38, $1441-1466$. 